\title{
The nature of the initial coping response and the learned helplessness effect
}

\author{
STEVEN F. MAIER and RAYMOND L. JACKSON \\ University of Colorado, Boulder, Colorado 80309
}

The availability of an effective coping response has been shown to attenuate the deleterious behavioral and physiological consequences of inescapable electric shock. In the current study, two groups of rats could escape tailshock by turning a wheel. When short-latency responses that appeared to be elicited by shock onset were permitted to terminate shock, rats subsequently failed to learn to escape in a shuttlebox and did not differ from rats which received an equivalent amount of inescapable shock. However, when a relatively long-latency response was required and short-latency responses were not allowed to affect shock, rats subsequently readily learned to escape in the shuttlebox. The implications of these results for explanations of the manner in which prior exposure to shock influences subsequent escape learning were discussed.

The behavioral and physiological consequences of aversive events are strongly affected by their escapability and/or avoidability. Exposure to inescapable electric shock frequently interferes with the subsequent acquisition of escape behavior, but exposure to equivalent amounts of escapable shock does not (Seligman \& Beagley, 1975; Seligman \& Maier, 1967). Inescapable shock also produces a later decrement in shock-elicited aggression, while escapable shock does not (Maier, Anderson, \& Lieberman, 1972). Finally, inescapable shock often produces more severe physiological symptoms of stress than does equivalent amounts of escapable and avoidable shock (Weiss, 1968, 1971a; Weiss, Stone, \& Harrell, 1970). Despite these pronounced effects of the presence of a coping or escape response, there have been only two studies designed to investigate the characteristics that an escape response must have to function as an effective coping response. What is meant by an effective coping response is one that counteracts whatever effects inescapable shock might have. In these studies, Weiss (1971b) found that providing exteroceptive feedback for an avoidance response reduced the gastric ulceration that occurred during training and that punishing a previously effective coping response was physiologically more deleterious than having no coping response at all (Weiss, 1971c).

In contrast with the dearth of information on the importance of the nature of the coping response, it is clear that the characteristics of the escape/ avoidance test task are crucial in determining whether prior exposure to inescapable shock will

This research was supported by Grant MH 26827 to Steven F Maier from the National Institute of Mental Health. Requests for reprints should be sent to Steven F. Maier, Department of Psychology, University of Colorado, Boulder, Colorado 80309. interfere with its acquisition. That is, the occurrence of what has been called the learned helplessness effect (for a review see Maier \& Seligman, 1976) is strongly dependent on the type of escape response that the subject is required to learn. Maier, Albin, and Testa (1973) found that inescapably shocked rats would fail to learn to escape in a shuttlebox if two crossings were required to terminate shock (FR 2), but would respond as well as controls if only one crossing was required (FR 1). However, inescapably shocked rats will fail to learn to cross once in a shuttlebox if shock termination is slightly delayed (Maier \& Testa, 1975, Experiment 2), and they will learn FR 2 escape like control subjects if shock briefly terminates after the first crossing of the FR 2 (Maier \& Testa, 1975, Experiment 1). Similarly, Seligman and Beagley (1975) found that inescapably shocked rats acquired a leverpress escape response at a normal rate when only a single response was required, but did not learn to make three leverpresses to escape. Maier, Jackson, Tomie, and Rapaport (Note 1) found that inescapably shocked rats would acquire an FR 3 leverpress escape response if a brief white noise was given as a feedback stimulus for each response of the FR 3 .

Maier, Albin, and Testa (1973) have noted that FR 1 shuttlebox escape latencies are very short and invariant across trials. Bolles and McGillis (1968) have made a similar observation with regard to FR 1 leverpressing. In this sense, FR 1 shuttling and FR 1 leverpressing seem highly reflexive, and thus the results discussed above suggest that exposure to inescapable shock does not interfere with the performance of reflexive escape responses. Perhaps the reflexiveness of the escape response given during the initial shock exposure might also be important. Turner and Solomon (1962) have shown that short- 
latency escape responses are not readily acquired as avoidance responses and seem to maintain a respondent character. This suggests the possibility that short- and long-latency escape responses might not be equally effective in preventing the interference with subsequent escape acquisition shown in subjects given inescapable shocks. The present experiment investigated this question by placing rats in a small wheel-turn box in which shock elicits a shortlatency (less than $.8 \mathrm{sec}$ ) movement of the wheel. One group was allowed to escape shock by making the short-latency response, and another group was required to escape by making a longer-latency wheel turn.

\section{METHOD}

\section{Subjects}

The subjects were 40 male albino rats obtained from the Holtzman Co., Madison, Wisconsin. They were 90-100 days old at the start of the experiment and were maintained on a 12-h dark-light cycle and ad-lib. food and water.

\section{Apparatus}

The initial treatment was given in three Plexiglas wheel-turn boxes modeled after those used by Weiss, Stone, and Harrell (1970). The walls of the apparatus were made of clear Plexiglas and the floors were made of Masonite. The chambers were $11.4 \mathrm{~cm}$ wide and $17.8 \mathrm{~cm}$ high. The tops of the chambers were $7.6 \mathrm{~cm}$ deep and the bottoms were $17.8 \mathrm{~cm}$ deep. Thus the end walls were at an angle and the top fit across the rat's back in such a way that the rat could not turn around in the chamber. A $6.4-\mathrm{cm}$-diam grooved Plexiglas wheel was located in the front of each chamber and extended $1.5 \mathrm{~cm}$ into the chamber. The force required to turn the wheel was roughly $50 \mathrm{~g}$ and was sufficient to prevent spinning of the wheel. The rat's tail extended through a hole in the rear of each apparatus and was taped to a Plexiglas rod. Each chamber was enclosed in a Lehigh Valley sound-attenuating chamber illuminated by a $71 / 2-W$ bulb.

Shocks from three Grason-Stadler E1064 GS shock sources modified to yield unscrambled outputs were delivered to electrodes which were augmented with electrode paste and taped to the rat's tail.

Escape-avoidance testing was conducted in a shuttlebox manufactured by Lehigh Valley. The shuttlebox was $46.7 \times 20.4 \times$ $19.7 \mathrm{~cm}$. The center of the shuttlebox contained a metal divider with a rounded archway $5.5 \mathrm{~cm}$ high and $4.5 \mathrm{~cm}$ wide cut out of it. Thus, to go from one side of the shuttlebox to the other, the rat was required to run through a hole. The height of the opening required the rat to crouch slightly. The shuttlebox was housed in a sound-attenuating chamber. The background noise was $75 \mathrm{~dB}$ SPL and the 1,000-Hz-tone conditioned stimulus (CS) added $5 \mathrm{~dB}$ to the background noise. Scrambled shock was delivered from a Grason-Stadler Model 700 shock source.

\section{Procedure}

Each rat was unsystematically assigned to one of five groups ( $N=8$ /group). Two groups first received one session of escape training in the wheel-turn boxes. The session contained 80 trials presented on a variable time schedule with a mean intertrial interval of $60 \mathrm{sec}$ and a range of $30-120 \mathrm{sec}$. The escape response requiremient was 1/4 turn of the wheel; shock terminated after $30 \mathrm{sec}$ if an escape response did not occur. For one escape group ( $E$-short), the first 1/4 turn of the wheel terminated shock. For the second escape group (E-Long) the first $1 / 4$ turn of the wheel which was completed more than $0.8 \mathrm{sec}$ following the onset of shock terminated the shock. That is, a wheel turn during the first $0.8 \mathrm{sec}$ of shock had no consequence. Shock intensity for all rats began at $0.8 \mathrm{~mA}$ and was increased to $1.0 \mathrm{~mA}$ on Trial 20 , to $1.3 \mathrm{~mA}$ on Trial 40, and to $1.6 \mathrm{~mA}$ on Trial 60 . This was done because pilot work revealed a deterioration of responding when shock intensity was constant.

Groups of rats (Y-Short and Y-Long) were yoked to each of the escape groups. Each rat in the yoked groups was assigned to one of the escape rats. Shock began simultaneously for both rats and was terminated for both whenever the escape subject made the required response.

A final group of rats $(R)$ was simply restrained in the apparatus for $1 \frac{1}{2} \mathrm{~h}$.

Thirty trials of escape-avoidance training in the shuttlebox occurred $24 \mathrm{~h}$ after the first session. The onset of the tone warning signal began each trial and remained until trial termination. The CS-UCS interval was $5 \mathrm{sec}$. If the rat completed the response requirement during this interval, the warning signal terminated and no shock occurred. Failure to complete the response during this interval produced a $0.6-\mathrm{mA}$ shock, which remained until the rat responded. If the rat failed to complete the response requirement within $35 \mathrm{sec}$ of warning signal onset, the trial automatically terminated and a $35-\mathrm{sec}$ latency was recorded. The mean intertrial interval was $60 \mathrm{sec}$; it 'ranged from 5 to $270 \mathrm{sec}$. On the first five trials, a single crossing of the shuttlebox (FR 1) was required to escape or avoid. Two crossings were required on the remaining 25 trials. This is the standard task previously used in this laboratory to assess learned helplessness effects (e.g., Maier et al., 1973).

\section{RESULTS}

The wheel-turn escape latencies for Groups E-Short and E-Long are shown in Figure 1. The latencies for the E-Short group represent the latency to the first $1 / 4$ turn of the wheel, whereas the latencies for the E-Long group represent the latency to the first $1 / 4$ turn of the wheel that followed shock onset by more than $0.8 \mathrm{sec}$. As can be seen, the mean latencies of the E-Short group were invariant across trials and remained close to $6 \mathrm{sec}$. However, the E-Long group displayed a pronounced acquisition function with decreasing latencies across trials. These impressions

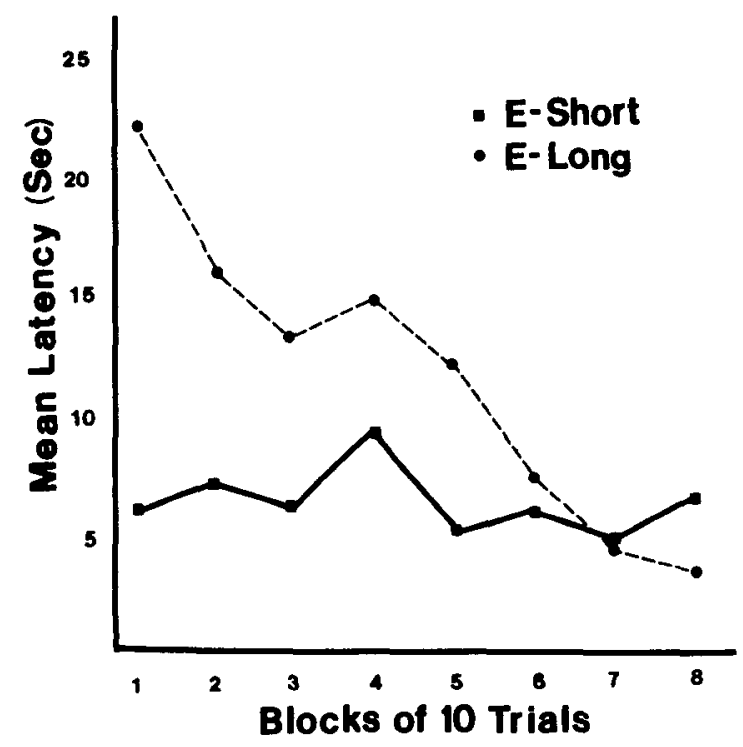

Figure 1. Mean wheel-lurn escape latency (seconds) for Groups E-Short and E-Long, across blocks of 10 trials. 
were confirmed by a repeated measures analysis of variance which revealed a reliable effect of groups $[F(1,14)=16.09, p<.01]$, trials $[F(7,98)=4.18$, $\mathrm{p}<.01]$, and the interaction of Groups by Trials $[F(7,98)=5.55, \mathrm{p}<.01)$.

Figure 1 does not accurately reflect the performance of the E-Short subjects. The mean latency was in the 6-sec range, but individual latencies of this length were quite rare. Table 1 shows the mean percentage of trials on which failure to respond occurred and the mean percentage of trials with latencies below $0.8 \mathrm{sec}$ across 10 trial blocks. Seventy-four percent of the trials were terminated with latencies less than $0.8 \mathrm{sec}$, and this did not change appreciably across trials. The remaining trials were split between failures to respond $(13 \%)$ and responses with latencies between 0.8 and $30 \mathrm{sec}(13 \%)$. Thus, the 6-sec latencies resulted from averaging together these very different responses. A plot of median rather than mean latencies would show latencies of $.7 \mathrm{sec}$.

The mean latencies shown in Figure 1 do accurately reflect the changes across trials of the effective escape response for the E-Long subjects. Table 1 also shows the average number of failures to escape for this group. Latencies of less than $0.8 \mathrm{sec}$ were not recorded for this group in a trial-by-trial manner but were only cumulated. As can be seen, failures to escape were initially very frequent and then decreased as training progressed. A repeated measures analysis of variance applied to the number of failures to escape for the two groups yielded a marginally reliable effect of groups $[\mathrm{F}(1,14)=3.80, \mathrm{p}<.10]$ and reliable effects of trials $[F(7,98)=2.19, p<.01]$ and the interaction of groups and trials $[F(7,98)=$ $4.20, p<.01]$. It should be noted that E-Long subjects did make short-latency wheel turns on many of the trials. Sixty-one percent of the trials contained such latencies. Thus, these subjects frequently made two $1 / 4$ turns of the wheel before shock terminated. However, these short-latency responses decreased across trials, and only $9 \%$ of the last 10 trials contained such responses.

The shuttlebox test performance of all groups is shown in Figure 2. As is typical, there were no reliable differences between groups on FR 1 trials $(\mathrm{F}<1)$. However, large differences between groups emerged on the FR 2 trials. Both inescapable shock

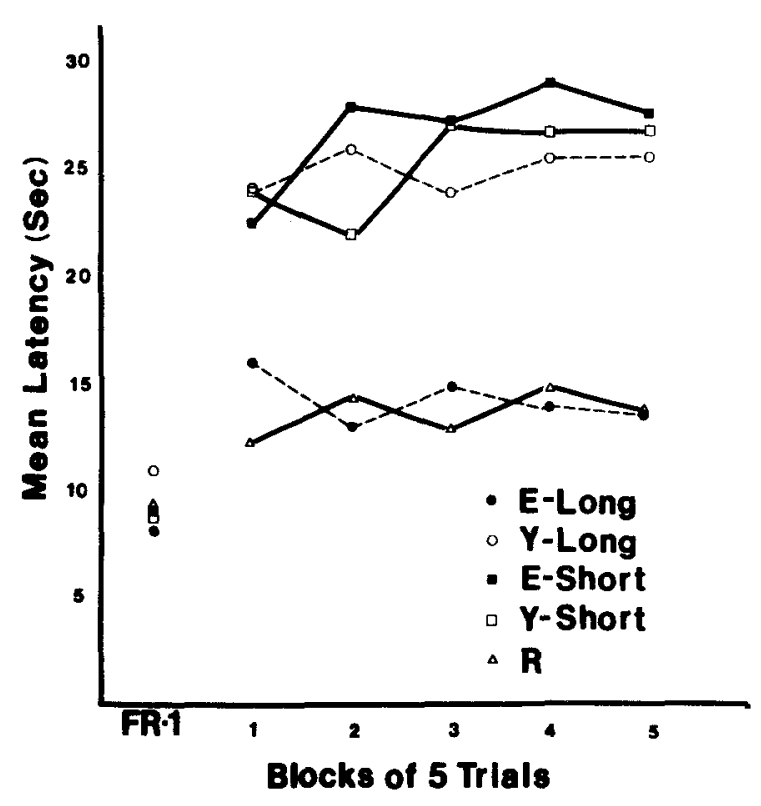

Figure 2. Mean shuttlebox response latency (seconds) across blocks of five trials.

groups (Y-Short, Y-Long) responded very slowly. More importantly, Group E-Short performed as poorly as did the inescapable shock groups, whereas Group E-Long responded as rapidly as did Group R. A repeated measures analysis of variance yielded a reliable effect only for groups $[\mathrm{F}(4,35)=4.19$, $p<.011$. Subsequent Duncan's multiple range tests $(\alpha=.05)$ revealed that Groups R and E-Long responded more rapidly than Groups E-Short, Y-Short, and Y-Long. No other differences approached significance.

In addition, the pattern of performance was similar in Groups E-Short, Y-Short, and Y-Long. If a criterion of four or more failures to escape in the last five trials is established as an indication of failure to learn to escape, five of the eight subjects in each of these groups failed to learn. Only one subject in Group R and one in Group E-Long failed to learn by this criterion. Table 2 shows mean latencies for these subgroups. As can be seen, the subjects that learned in the different groups showed comparable latencies and the subjects that did not learn showed similar latencies in the different groups. Also, the latencies of the nonlearners appeared to increase across FR 2 trials. It was not possible to

Table 1

Mean Percentage of Trials on Which Failure to Escape Occurred for Groups E-Short and E-Long, and Mean Percentage of Trials With Latencies Below .8 Sec for Group E.Short, Across Blocks of 10 Trials

\begin{tabular}{|c|c|c|c|c|c|c|c|c|}
\hline & \multicolumn{8}{|c|}{ Trial Block } \\
\hline & 1 & 2 & 3 & 4 & 5 & 6 & 7 & 8 \\
\hline Failures: E-Short & 15 & 10 & 8 & 20 & 15 & 15 & 8 & 10 \\
\hline Failures: E-Long & 50 & 35 & 20 & 30 & 18 & 15 & 5 & 3 \\
\hline Latencies $<.8$ sec: E-Short & 75 & 65 & 70 & 63 & 85 & 78 & 80 & 73 \\
\hline
\end{tabular}


Table 2

Mean Escape Latencies for FR1 and Blocks of Five FR2 Trials, Subjects That Did and Did Not Learn the Escape Task

\begin{tabular}{|c|c|c|c|c|c|c|c|}
\hline & \multirow[b]{2}{*}{$\mathbf{N}$} & \multirow[b]{2}{*}{ FR1 } & \multicolumn{5}{|c|}{ Trial Block } \\
\hline & & & 1 & 2 & 3 & 4 & 5 \\
\hline Y-Long: Nonlearners & 5 & 11.46 & 25.12 & 32.56 & 33.13 & 33.97 & 34.15 \\
\hline Y-Long: Learners & 3 & 9.53 & 23.20 & 15.12 & 9.29 & 12.08 & 12.18 \\
\hline Y-Short: Nonlearners & 5 & 8.14 & 28.01 & 27.63 & 35.00 & 35.00 & 35.00 \\
\hline Y-Short: Learners & 3 & 7.96 & 17.64 & 12.79 & 13.96 & 12.63 & 13.45 \\
\hline E-Short: Nonlearners & 5 & 8.12 & 24.80 & 33.99 & 34.86 & 35.00 & 34.96 \\
\hline E-Short: Learners & 3 & 8.08 & 17.81 & 18.34 & 14.33 & 14.60 & 13.95 \\
\hline E-Long: Nonlearners & 1 & 7.72 & 26.11 & 24.20 & 33.43 & 33.19 & 30.00 \\
\hline E-Long: Learners & 7 & 7.80 & 13.98 & 10.83 & 12.26 & 11.46 & 11.75 \\
\hline R: Nonlearners & 1 & 9.01 & 20.87 & 26.91 & 24.61 & 30.65 & 35.00 \\
\hline R: Leamers & 7 & 8.84 & 10.83 & 12.32 & 10.79 & 12.59 & 12.49 \\
\hline
\end{tabular}

statistically analyze these data as a whole, since two of the subgroups contained only one subject. However, two analyses were performed. First, a repeated measures of analysis of variance was applied to the data from the three groups which showed an interference with escape acquisition (Y-Short, Y-Long, E-Short). The learners were reliably faster than the nonlearners $[F(2,18)=5.90, \dot{p}<.05]$, while the initial escape training condition had no reliable effect $(F<1)$. The only reliable interaction was learners vs. nonlearners by Trials $[\mathrm{F}(3,72)=2.19, \mathrm{p}<.05]$. This supports the observation that the nonlearners were becoming slower across trials. A second analysis of variance was applied to the learners from all groups. None of the comparisons reached conventional levels of statistical significance. Finally, two parallel analyses of variance were applied to the FR 1 latencies. No reliable differences emerged.

\section{DISCUSSION}

The results of the present experiment are clear. The rats that were initially allowed to make shortlatency escape responses subsequently performed as poorly in the shuttlebox escape task as did the rats that were initially exposed to inescapable shock. In contrast, the rats that initially made long-latency escape responses subsequently escaped as rapidly in the shuttlebox as rats that had only been restrained. Thus, the nature of the escape or coping response does strongly effect whether the initial exposure to shock will interfere with later escape behavior.

A comment concerning the form of the shuttlebox data shown in Figure 2 is in order. The groups that performed well in the shuttlebox did not show an acquisition curve of decreasing latencies for the FR 2 escape responses. Thus it might appear that the FR 2 task is of the sort that Maier, Albin, and Testa (1973) showed to be insensitive to prior exposure to inescapable shock. However, it should be remembered that the FR 2 trials were preceded by five FR 1 trials. This prior training should produce "artificially" short latencies on the first few FR 2 trials and so it should not be surprising that an acquisition curve is not evident. We have found (unpublished data) that if the FR 2 trials are not preceded by FR 1 trials, some control subjects do not learn to escape. However, those that learn do show an acquisition curve with decreasing latencies. Figure 3 shows the mean performance of six out of eight rats that did learn. The decrease in latency is reliable, as there is no overlap between the mean latencies for the first and fifth blocks.

The terminal FR 2 escape latencies in Groups ELong and R were roughly $14 \mathrm{sec}$. It might seem that such a latency would not be asymptotic and that further training would produce decreased escape latencies and thus an acquisition curve. However, a number of points about these data should be clarified. First, the escape procedure involves a 5 -sec CS-UCS interval. Thus, the latency in the presence of shock was $9 \mathrm{sec}$ rather than 14. In addition, one rat in both the E-Long and the $\mathrm{R}$ groups did not learn to escape and so received latency scores of $35 \mathrm{sec}$. This obviously inflates the mean time to respond. If these rats are removed, the mean latency becomes

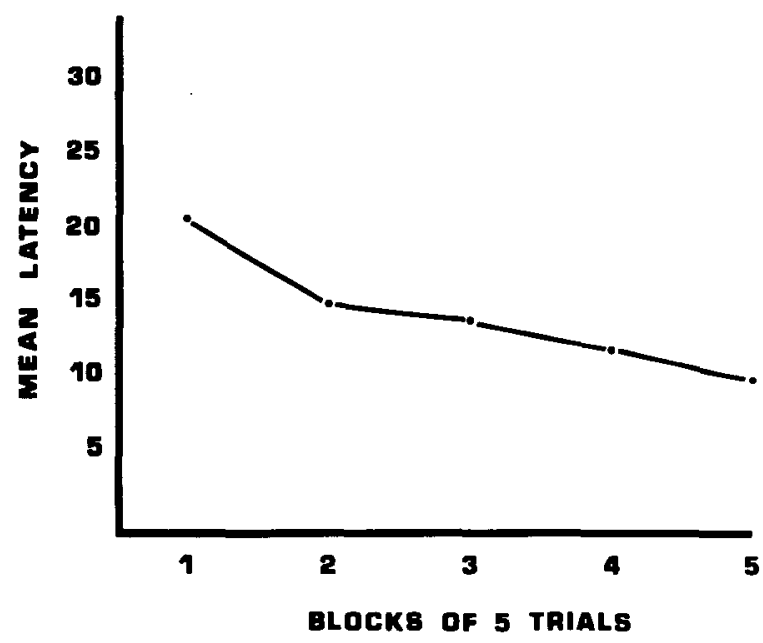

Figure 3. Mean shuitlebox response latency (seconds) across blocks of five trials. 
roughly $5 \mathrm{sec}$, not counting the CS-UCS interval, and our rats simply do not come to make FR 2 escapes at a faster speed than this using the present archway barrier and shock intensity, even after many trials. However, if should be reemphasized that performance does begin at a much poorer level (Figure 3) if the FR 2 trials are not preceded by FR 1 trials. Those rats that do learn under such a procedure come to eventually respond with the same 5 -sec latency as reported here.

The use of the small wheel-turn boxes in the present study produced escape responding that might be called reflexive, respondent, or elicited. Shockevoked wheel turns with latency of less than $0.8 \mathrm{sec}$ occurred on $74 \%$ of the trials, and the latencies did not change across the 80 trials. In their analysis of the concept of reflexiveness, Turner and Solomon (1962) argued that latency and probability of response were the most important defining features of a reflexive response, and responding in the E-Short condition seems to meet their criteria for high reflexiveness.

As expected, the E-long condition showed a different pattern of responding. On early trials, rats in this group would frequently emit a short-latency response and fail to emit a second response during the remainder of the trial. However, although failures to escape were common at the beginning of training, the likelihood of failure decreased across trials. Moreover, although responses with latencies of less than $0.8 \mathrm{sec}$ were frequently made, the required longerlatency responses also occurred, and the latency of these responses decreased as training progressed.

There are a number of possible explanations for the fact that the E-Short subjects were later retarded in escape acquisition. For example, Weiss (1971a) has argued that a coping response is effective in preventing deleterious physiological reactions to stress to the degree to which it provides relevant feedback. According to Weiss, relevant feedback is provided by cues which are not associated with the stressor. Thus, exteroceptive and response-produced stimuli can serve as relevant feedback if the occurrence of these cues is followed by a stressor-free interval of time. Although Weiss' arguments might be applicable to the current experiment, we are not sure exactly how to do so. It is not entirely clear how not allowing responses of less than $.8 \mathrm{sec}$ to terminate shock would increase the amount of relevant feedback in the situation. Although a number of tentative speculations could be advanced, it seems appropriate to temporarily hold Weiss' arguments in abeyance.

Maier and Seligman (1976), Maier, Seligman, and Solomon (1969), and Seligman, Maier, and Solomon (1971) have argued that the learned helplessness effect is produced by learning that shock termination is independent of voluntary responding during exposure to inescapable shock. According to this account, escapable shock does not typically produce learned helplessness because the subject learns that shock termination does depend on voluntary responding. It is important to note that Maier and Seligman (1976, p. 17) maintained that what is crucial is not the mere presence or absence of an escape response but rather the cognitive representation that the shock is or is not escapable.

Turner and Solomon (1962) manipulated the reflexiveness of the escape response given to human subjects in an escape-avoidance situation. Reflexive responses were defined as ones with a high probability and a latency below $0.7 \mathrm{sec}$. The most reflexive escape response they required was a movement of the big toe of the right foot when shock was being delivered to the right ankle. The least reflexive response required the subject to slide a knob back and forth by hand when shock was delivered to the right ankle. Turner and Solomon found that subjects given a reflexive escape response would not learn to make this response to avoid shock, but subjects given a less reflexive escape response would readily learn to make this response as an avoidance response. Questioning revealed that those subjects with reflexive escape responses were not able to verbalize the escape contingency, and that they were not even aware that it was their behavior that terminated shock. Turner and Solomon stated that the subjects in the high-reflexiveness condition "gave no hint that they considered the experimental situation as one in which a problem was involved or any learning might be occurring"' (p. 11). They further noted, "The subjects in groups T-M and TT-M (high reflexiveness) appeared to be failing to learn to avoid because the shock elicited a toe movement too quickly for these subjects to find out what had happened. The verbal responses indicated that these subjects attributed shock duration to the action of the experimenter, or to some preset experimental condition" (p. 22). In our terms, Turner and Solomon found that subjects given a reflexive escape response viewed shock as being uncontrollable. Turner and Solomon went on to argue that short-latency responses might have primarily respondent characteristics and so not be sensitive to response-reinforcement contingencies. Finally, it should be noted that initially telling the subjects that there was something that they could do to terminate shock increased the latency of the toe flexion responses beyond $.7 \mathrm{sec}$, produced avoidance learning in these groups, and led to an awareness of the escape contingency.

It is obviously hazardous to extrapolate from the data of the human subjects discussed above to the rats used in the present study. However, it should be noted that animals do have difficulty learning to avoid when the response is of short latency (see Turner and Solomon, pp. 24-25). 
If such an extrapolation is made, the argument is obvious. The E-Short subjects may not have learned about the contingency between their own behavior and shock termination since their escape response was reflexive. Thus, the Maier and Seligman position would expect these subjects to later fail to learn to escape just as do subjects given inescapable shock.

It is not clear whether other explanations of the learned helplessness effect can account for the present data. Glazer and Weiss $(1976 \mathrm{a}, \mathrm{b})$ have argued that the learned helplessness effect studied in rats can be explained as learned inactivity. The inescapable shocks delivered in the standard experiment in our laboratory are $5 \mathrm{sec}$ long. Weiss argued that the rat's activity generally declines after 3 or $4 \mathrm{sec}$ of shock, and that this activity decline is soon followed by shock termination. Thus, inactivity is reinforced. While it might be reasonable to argue that the E-Long condition maintained more activity than the E-Short condition, this position encounters difficulty in explaining why the E-Short subjects should later perform as poorly as did the $Y$ groups. The argument would have to be that inactivity was reinforced in the E-Short group. However, if activity does decrease only after 3 or $4 \mathrm{sec}$ of shock, it is difficult to see how inactivity could have been reinforced. Seventy-four percent of the trials ended in less than $.8 \mathrm{sec}$ of shock. Such trials could not reinforce an activity decrease if activity takes 3 or $4 \mathrm{sec}$ to decline. Further, such trials would not reinforce an activity decrease anyway, since they were terminated by an active response. On $13 \%$ of the trials, no response occurred and shock was thus maintained for $30 \mathrm{sec}$. If activity decreases after 3 or $4 \mathrm{sec}$, then these trials would entail too long a delay of reinforcement to reinforce inactivity. Actually, such trials should punish inactivity. This leaves only $13 \%$ of the trials with shock of a duration between .8 and $30 \mathrm{sec}$. Only $1 / 6$ of these trials had a latency between 5 and $10 \mathrm{sec}$. Thus, only $2 \%$ of the 80 trials had a shock duration which might be said to reinforce an activity change occurring 3 or $4 \mathrm{sec}$ after shock onset. The same argument applies to the Y-Short condition. Only group Y-Long had an appreciable number of trials with durations that might reinforce an activity decrease, but Groups E-Short, Y-Short, and Y-Long performed equally poorly in the test situation.

Levis (1976) has proposed an explanation somewhat similar to Weiss' learned inactivity view. He argued that when a response regularly precedes shock termination, it is reinforced by pain reduction through traditional mechanisms. When no escape response is available, immobility is said to be reinforced. Levis argued that the onset of shock elicits movement and that the continued presentation of shock following the onset period punishes this movement. Further, the animal is inactive following shock termination, and this is said to be reinforced by fear reduction. Thus, the frequency of inactivity should increase during shock presentation and, as with escape responses, should now be reinforced by shock offset. This hypothesis has difficulties similar to Weiss' in accounting for the behavior of E-Short subjects. These subjects later failed to learn to escape, even though immobility should have not been reinforced because wheel turns were immediately followed by shock termination. Further, if shock onset does produce activity, activity should have been reinforced on $74 \%$ of the trials for the Y-Short subjects. This is because shock was $.8 \mathrm{sec}$ or less on $74 \%$ of the trials, and thus shock offset should have closely followed any activity increases produced by shock onset. Immobility could have been reinforced on the remaining $26 \%$ of the trials, but it is hard to see how the net effect would have been a reinforcement of inactivity. Further, half of those trials lasted $30 \mathrm{sec}$ and would thus have entailed a considerable delay of reinforcement. Therefore, it is not clear from this position why the Y-Short subjects should later have performed as poorly as the Y-Long subjects.

A somewhat different competing motor response hypothesis offered by Bracewell and Black (1974) might be better able to explain the present data. They argued that inescapable shock punishes movement because it might hurt more to move than to not move during shock. It is possible that movement was equally punished in the E-Short, Y-Short, and Y-Long conditions. However, it should be noted that the YLong subjects received almost twice as much shock as did the others, but later performed indistinguishably from them. It might have been expected that more shock should have produced greater punishment of movement. However, this argument should be tempered by the possibility that a ceiling might have been reached. It should also be noted that the wheel-turn escape latencies of the E-Short subjects did not change across trials and so a movement punishment effect was not obvious. Again, this is not a strong argument, as movement and wheel turns are not necessarily isomorphic. Finally, it should be recognized that Bracewell and Black must assume that movement is not punished if shock terminates shortly after an active response. If this assumption is not made, the usual escape-yoke difference cannot be explained. Shock frequently terminated following an active response for E-Short subjects, yet they later failed to learn to escape.

The present data also have implications for a possible artifact that has existed in escape-yoked designs of studies on learned helplessness. Church (1964) has argued that yoked-control designs in general introduce a systematic error which could account for the outcome of experiments using these designs. 
Applied to the escape-yoked case, the argument makes the reasonable assumption that there are individual differences between rats in the effectiveness of shock. To simplify the exposition, assume that shock is effective for some rats and ineffective for others. If it is assumed that subjects for which shock is effective will escape more rapidly than subjects for which shock is ineffective, all subjects in the escape condition for which shock is effective will receive relatively short shocks and all subjects for which shock is ineffective will receive relatively long shocks. Obviously, this will not be the case for the yoked subjects. Some for which shock is effective will be yoked to escape subjects for which shock is ineffective and will thus receive long shocks, and some for which shock is ineffective would be yoked to subjects for which shock is effective and thus receive short shocks. The net effect would be that the subjects in the yoked group for which shock is effective receive more shock than do subjects in the escape group for which shock is effective. Conversely, subjects in the yoked group for which shock is ineffective receive less shock than the corresponding escape group subjects. This asymmetry should have more impact on yoked subjects for which shock is effective since, by definition, they are more reactive to shock. The net result could be a bias analogous to delivering more shock to the yoked than to the escape group, and this factor, rather than control of shock, might account for a later inferiority of the yoked group. Thus, it can be argued that the experiments by Seligman and Beagley (1975) and Seligman and Maier (1967) do not definitively implicate control of shock as the crucial variable in producing the learned helplessness effect.

The way to test this argument is to yoke all of the yoked group subjects to escape subjects for whom shock is effective. This is because the bias is produced by the pairing of yoked effective and escape ineffective subjects. That is, the desired strategy would be to systematically provide the yoked subjects with less shock than the escape group received on the average (see Maier et al., 1972). Although the present experiment was not designed to accomplish this purpose, the fact that all of the $\mathrm{Y}$ Short subjects received less shock than all of the E-Long subjects allows a comparison between escapable and inescapable shock groups which is not confounded by the potential artifact noted above. Even though the E-Long subjects received almost twice as much shock as the Y-Short subjects, the latter subjects later escaped poorly while the former subjects escaped efficiently. Thus it would appear that the escape-yoked difference cannot be attributed to an asymmetry in effective shock duration and is produced by the escapability of the shock.

In conclusion, the present experiment demon- strates that the nature of the initial escape response is important in determining whether exposure to shock will interfere with subsequent escape acquisition. Rats allowed to escape shock by making a short-latency response later failed to acquire shuttlebox escape, while rats forced to escape by making a longer-latency escape response performed shuttlebox escape normally. We believe that this outcome resulted from the differential effect of reflexive and nonreflexive escape responses in permitting the animal to learn about the relation between its behavior and outcomes.

\section{REFERENCE NOTE}

1. Maier, S. F., Jackson, R. L., Tomie, A., \& Rapaport, P. M. How to get learned helplessness in rats. Paper presented at the meetings of the Psychonomic Society, Denver, 1975.

\section{REFERENCES}

Bolles, R. C., \& McGillis. D. B. The non-operant nature of the bar press escape response. Psychonomic Science, 1968, 11 , $261-263$.

BraCEWELL, R. J., \& BLACK, A. H. The effects of restraint and noncontingent pre-shock on subsequent escape learning in the rat. Learning and Motivation, 1974, 5, 53-69.

СнuRch, R. M. Systematic effect of random error in the yoked control design. Psychological Bulletin, 1964, 62, 122-131.

GlazER, H. I., \& WEISS, J. M. Long term and transitory interference effects. Journal of Experimental Psychology: Animal Behavior Processes, 1976, 2, 191-202. (a)

Glazer, H. I., \& WEIss, J. M. Long term interference effect: An alternative to learned hleplessness. Joumal of Experimental Psychology: Animal Behavior Processes, 1976, 2, 202-213. (b)

Levis. D. J. Learned helplessness: A reply and an alternative S-R interpretation. Journal of Experimental Psychology: Animal Behavior Processes, 1976, 105, 47-66.

Maier, S. F., Albin, R. W., \& Testa, T. J. Failure to escape in rats previously exposed to inescapable shock depends on nature of escape response. Journal of Comparative and Physiological Psychology, 1973, 85, 581-592.

Maier, S. F., Anderson, C., \& Lieberman, D. A. Influence of control of shock on subsequent shock elicited aggression. Journal of Comparative and Physiological Psychology, 1972, 81, 94-100.

Maier, S. F., \& Seligman, M. E. P. Learned helplessness: Theory and evidence. Journal of Experimental Psychology: General, 1976. 105, 3-46.

Maier, S. F., Seligman, M. E. P., \& Solomon, R. L. Pavlovian fear conditioning and learned helplessness. In B. A. Campbell \& R. M. Church (Eds.), Punishment. New York: AppletonCentury-Crofts, 1969.

MaIer, S. F., \& Testa, T. J. Failure to learn to escape by rats previously exposed to inescapable shock is partly produced by associative interference. Journal of Comparative and Physiological Psychology, 1975, 88, 554-564.

Seligman, M. E. P., \& Beagley, G. Learned helplessness in the rat. Journal of Comparative and Physiological Psychology, 1975. 88. 534-541.

Seligman, M. E. P., \& Maier, S. F. Failure to escape traumatic shock. Journal of Experimental Psychology, 1967, 74, 1-9.

Seligman, M. E. P., Maier, S. F., \& Solomon, R, L. Unpredictable and uncontrollable aversive events. In F. R. Brush (Ed.), Aversive conditioning and learning. New York: Academic Press, 1971.

Turner, L. H., \& Solomon. R. L. Human traumatic avoidance learning: Theory and experiments on the operant-respondent dis- 
tinction and failures to learn. Psychological Monographs: General and Applied, 1962. 76, Whole No. 559, 1-33.

WEISS. J. M. Effects of coping responses on stress. Journal of Comparative and Physiological Psychology, 1968, 56, 251-260.

WEIss. J. M. Effects of coping behavior in different warning signal conditions on stress pathology in rats. Journal of Comparative and Physiological Psychology, 1971, 77, 1-13. (a)

WEIss, J. M. Effects of coping behavior with and without a feedback signal on stress pathology in rats. Journal of Comparative and Physiological Psychology. 1971, 77. 22-30. (b)
WEISS, J. M. Effects of punishing the coping response (conflict) on stress pathology in rats. Joumal of Comparative and Physiolog ical Psychology, 1971, 77. 14-21. (c)

Weiss, J. M., Stone, E. A., \& Harrell, N. Coping behavior and brain norepinephrine in rats. Journal of Comparative and Physiological Psychology, 1970, 72, 153-160.

(Received for publication April 11, 1977; revision accepted July $17,1977$. 